\title{
PERFIS LINGUÍSTICOS DE SURDOS BILÍNGUES: UM ESTUDO EXPLORATÓRIO
}

\section{LANGUAGE PROFILES OF BILINGUAL DEAF INDIVIDUALS: AN EXPLORATORY STUDY}

\author{
Giselli Mara da Silva ${ }^{1}$
}

\begin{abstract}
RESUMO: Este estudo pretendeu descrever, de forma exploratória, aspectos ligados à história linguística dos participantes e os domínios de uso da Libras e do português no cotidiano. Para tanto, foram exploradas contribuições oriundas dos estudos do bilinguismo, especialmente a visão de bilinguismo focada no uso, considerando o Princípio da Complementaridade, além de estudos sobre o bilinguismo intermodal. Foram conduzidas entrevistas com 14 surdos usuários da Libras e do português. A análise do perfil dos entrevistados aponta para importantes fatores, como o período de ocorrência da surdez, a idade e a forma de contato com a Libras e as possibilidades de desenvolvimento da oralidade. A análise também indicou que a Libras e o português assumem diferentes funções para os surdos, como propõe o Princípio da Complementaridade. Porém, há algumas questões a serem consideradas em relação às possibilidades de uso das modalidades envolvidas.
\end{abstract}

PALAVRAS-CHAVE: Bilinguismo dos Surdos; Bilinguismo Intermodal; Libras; Português.

ABSTRACT: This study aims to describe, in exploratory form, aspects connected to the language history of the participants and the domains of use of Libras and Portuguese. In order to achieve that, contributions were explored from bilingualism studies, specially the view of bilingualism focused in usage, considering the Complementarity Principle, as well as studies about intermodal bilingualism. Semi-structured interviews were conducted with 14 bilingual deaf individuals. The analysis of the interviewee's profiles points to important factors, namely, the period of occurrence of deafness, the age of contact with Libras and the form of contact and the development of orality possibilities. The analysis also indicated that Libras and Portuguese have different functions for the deaf, as stated by the Complementarity Principle. However, there are some issues to be considered regarding the possibilities of using the modalities involved.

KEYWORDS: Intermodal Bilingualism; Bilingualism of the Deaf; Brazilian Sign Language; Portuguese.

Introdução

Nos últimos anos, as definições de bilinguismo têm-se distanciado de perspectivas

\footnotetext{
${ }^{1}$ Doutoranda em Estudos Linguísticos pela UFMG. Professora na FALE-UFMG.
} 
restritas, pautadas no controle nativo nas línguas, para definições mais amplas, em que se admite maior variação nos níveis de competência e se considera o uso das línguas pelos bilíngues (MACKEY, 2000; EDWARDS, 2013). Grosjean (2008, 2013), por exemplo, define o bilinguismo como o uso de duas ou mais línguas (ou dialetos) na vida cotidiana, ressaltando que tal definição é mais realista, por abarcar um número maior de bilíngues. Nessa perspectiva, considera-se que o bilíngue vai desenvolver a proficiência nas línguas conforme sua história linguística e a necessidade de uso das línguas em diferentes situações do cotidiano, ressaltando-se a função que as línguas desempenham na vida dos bilíngues conforme a situação de bilinguismo vivida. Para explicar essas diferentes funções, Grosjean propôs o Princípio da Complementaridade, em que se estabelece que os bilíngues usam suas línguas para diferentes propósitos, em diferentes domínios e com diferentes pessoas (GROSJEAN, 2008).

Considerando essa perspectiva de bilinguismo, pretende-se focar, neste artigo, na situação de bilinguismo vivenciada por surdos do Brasil, usuários da Língua de Sinais Brasileira (Libras) e do português brasileiro. Esses bilíngues usam duas línguas de modalidades diferentes - uma língua de sinais (LS) e uma língua falada - e apresentam semelhanças e diferenças em comparação aos bilíngues usuários de duas línguas faladas. Apesar de Grosjean (2008) afirmar que o Princípio da Complementaridade se aplica no caso de bilíngues surdos intermodais ${ }^{2}$, até onde sabemos não há trabalhos que comprovem esse Princípio no caso do bilinguismo de surdos e/ ou analisem como as línguas desses bilíngues se distribuem em diferentes domínios de uso. Sendo assim, o objetivo deste trabalho é descrever, de forma exploratória, aspectos ligados à história linguística de surdos bilíngues do par Libras-português e os domínios de uso da Libras e do português no cotidiano.

Nos últimos anos, temos alcançado muitos avanços em termos do reconhecimento de direitos da comunidade surda, sejam linguísticos ou de outra ordem e em termos da descrição da Libras (ver, por exemplo, QUADROS, 2013), bem como avanços em estudos do bilinguismo, voltados à descrição da aquisição da linguagem por bilíngues intermodais, surdos e ouvintes (CRUZ; PIZZIO; QUADROS, 2015; QUADROS; PIZZIO; CRUZ; SOUSA, 2016; entre outros), bem como aqueles voltados aos padrões de uso das línguas por bilíngues ouvintes (SOUSA; QUADROS, 2012). Porém ainda necessitamos avançar no que tange aos estudos sobre padrões de uso das línguas por bilíngues surdos adultos, bem como em trabalhos sobre processamento da linguagem por esses bilíngues. Assim, este trabalho se

\footnotetext{
${ }^{2}$ Usamos o termo intermodal (ou bimodal) para nos referir a um tipo de bilinguismo que envolve duas línguas de modalidades diferentes - uma LS e uma língua falada. O uso de tal termo não está relacionado a quaisquer abordagens educacionais que orientam o uso simultâneo das duas línguas, como é o caso da Comunicação Total.
} 
justifica pela necessidade de contribuir com uma compreensão mais acurada do bilinguismo dos surdos, o que tem implicações em várias esferas como, por exemplo, na definição de políticas linguísticas e na seleção de participantes para pesquisas.

\section{Bilinguismo e Princípio da Complementaridade}

De acordo com Grosjean (2016), a Linguística e, especialmente, a Sociolinguística têm-se interessado nas funções das línguas para o bilíngue e, particularmente, na escolha das línguas em diferentes situações. Para se compreender tal questão, as propostas pioneiras já colocavam a importância de se considerarem os fatores que podem influenciar na escolha de uma língua numa dada situação comunicativa, tais como os tópicos preferencialmente discutidos em uma das línguas, funções internas e externas das línguas, etc. Considerando a importância dos estudos sociolinguísticos e o impacto das funções e da escolha das línguas pelo bilíngue no processamento da linguagem, Grosjean propôs o chamado Princípio da Complementaridade, enunciado da seguinte forma: "Bilíngues normalmente adquirem e usam suas línguas para diferentes propósitos, em diferentes domínios, com diferentes pessoas. Diferentes aspectos da vida frequentemente demandam diferentes línguas" (GROSJEAN, 2008, p.23).

Esse princípio busca explicar as diferentes funções que as línguas desempenham no cotidiano dos bilíngues, conforme a situação de bilinguismo vivida. Dito de outro modo, diferentes situações de bilinguismo, geradas por imigração, por questões educacionais, profissionais, pessoais, etc., vão colocar aos indivíduos também diferentes necessidades de uso das línguas. Por exemplo, um imigrante pode utilizar a língua nativa em casa, enquanto utiliza a língua oficial do país onde vive no domínio profissional e no domínio escolar. E se refinarmos ainda mais a análise, considerando as modalidades de uso dessas línguas nesses domínios (oral, escrita ou sinalizada), pode-se compreender que diferentes modalidades podem cobrir também diferentes domínios. Nessa perspectiva, não se espera que um bilíngue domine igualmente as duas línguas em todas as modalidades (oral ou sinalizada e escrita) e em todas as quatro habilidades (compreensão e produção da língua oral ou sinalizada e compreensão e produção da escrita). Pelo contrário, considera-se que o bilíngue vai desenvolver a fluência conforme sua história linguística e a necessidade de uso das línguas no cotidiano, em diferentes domínios de sua vida (GROSJEAN, 2008, 2013, 2016). Inicialmente, a proposta do Princípio da Complementaridade baseou-se em observações nos estudos da Sociolinguística, em teorização e raciocínio linguísticos e em testemunhos de bilíngues; 
porém, nos últimos anos, como relata Grosjean (2016) em ampla revisão da literatura, evidências a favor desse Princípio começam a aparecer (ver, por exemplo, CARROL; LUNA, 2011).

\section{O Bilinguismo dos Surdos}

A despeito do uso das LS pelas comunidades surdas ao longo da história, a condição de bilinguismo vivida por essas populações foi reconhecida somente recentemente na Linguística (ANN, 2001; GROSJEAN, 2008) - mais especificamente a partir dos anos 1960, com o reconhecimento das LS como línguas genuínas (STOKOE, 1960). A partir de então, progressivamente, as comunidades surdas passam a ser reconhecidas como minorias linguísticas, e os surdos começam a ser considerados como sujeitos potencialmente bilíngues. Diz-se "potencialmente bilíngues", pois as condições de acesso dos surdos à LS usada pela comunidade surda local e a língua oficial de seu país ${ }^{3}$ não são simples; pois envolvem questões sociais, culturais e biológicas complexas. Inicialmente, é importante destacar que o acesso dos surdos às duas línguas é determinado por dois fatores não usuais no caso de outras minorias linguísticas: (i) o estatuto desigual das línguas no nível da transmissão pais-crianças, já que se estima que mais de $90 \%$ dos surdos sejam filhos de pessoas ouvintes (ii) o acesso desigual às línguas (não há acesso ao input auditivo ou esse é limitado) (PLAZA-PUST, 2012).

Assim, a maioria dos surdos não vai adquirir a LS - uma língua acessível a eles por meio da visão - no ambiente familiar, mas sim em outros espaços onde haja usuários dessa língua, como nas escolas, programas para crianças surdas, associações de surdos, etc. Devido a tais questões, uma das principais diferenças dos surdos em relação a outros grupos de bilíngues diz respeito à alta variação na idade de aquisição da primeira língua (L1) (BOUDREAULT; MAYBERRY, 2006; MAYBERRY, 2007; QUADROS; CRUZ, 2011). Já a aquisição da língua oficial vai depender de ensino formal: o desenvolvimento da fala está condicionado ao tratamento fonoaudiológico; e a língua escrita, por sua vez, pode ser aprendida na escola ou em outras instâncias de atendimento educacional. Essas questões que envolvem o acesso dos surdos à LS e à língua majoritária vão ter impacto no perfil dos surdos, resultando em grande diversidade de surdos no que tange aos níveis de proficiência nas duas línguas.

\footnotetext{
${ }^{3}$ As situações de bilinguismo vivenciadas pelas comunidades surdas ou por indivíduos surdos não se restringem ao uso de uma LS e a língua oral oficial. A esse respeito, ver, por exemplo, o trabalho de Morales-López e colaboradores (2002).
} 
Grosjean (2008), ao comparar o bilinguismo dos surdos e o bilinguismo de línguas orais, destaca como os bilíngues surdos são diversos como os bilíngues ouvintes, sendo que alguns fatores interferem nessa diversidade, como o nível de perda auditiva, o período em que ocorreu a surdez, a língua usada na infância, o tipo de educação, entre outros (GROSJEAN, 1992, 2008). Porém, os bilíngues surdos apresentam algumas especificidades, e uma delas é o fato de os padrões de conhecimento e de uso da linguagem parecerem ser diferentes e provavelmente mais complexos que no caso dos bilíngues de línguas faladas. Como se explicou anteriormente, os padrões de conhecimento das línguas vão ser influenciados, por exemplo, pelas condições de acesso a essas línguas desde a infância. Já em relação aos padrões de uso, os comportamentos diversos são o resultado de um número de fatores complexos, dentre os quais destacamos aqui os canais de produção envolvidos no bilinguismo dos surdos e a forma como atendem às línguas (GROSJEAN, 2008). Grosjean (2008) apresenta as habilidades e modalidades envolvidas no bilinguismo dos surdos, retratando as possibilidades em termos de produção e percepção das três modalidades de língua - oral, escrita e sinalizada ${ }^{4}$. No que tange à LS, os surdos sinalizam e compreendem as sinalizações, além de poderem usar a LS escrita, dado o desenvolvimento recente de um sistema de escrita, chamado SignWritting ${ }^{5}$. No caso da língua majoritária, os surdos em geral aprendem a ler e escrever na escola, podendo também, por meio de tratamento fonoaudiológico, aprender a falar e a ler os lábios. Além disso, os surdos podem usar sistemas de representação manual da língua falada, dando origem a versões sinalizadas das línguas majoritárias ${ }^{6}$.

Porém, é importante destacar que os bilíngues surdos precisam lidar com questões relativas às possibilidades de desenvolvimento da oralidade e da compreensão auditiva e também com questões relativas à língua da comunicação face a face e a língua da escrita, o que vai perpassar todos os domínios de uso das línguas. Como explica Grosjean (2008), para os bilíngues surdos, certas habilidades na língua majoritária podem não ser nunca completamente desenvolvidas, como é o caso da produção oral. Além disso, afirma-se que a leitura labial é considerada um meio de comunicação pouco consistente e confortável para os surdos (BOTELHO, 1999). Assim, ainda que os surdos utilizem o português em interações face a face, em muitos casos, a LS é a língua escolhida e considerada a mais confortável,

\footnotetext{
${ }^{4} \mathrm{O}$ autor listou também a soletração manual, que foi considerada como pertencente às duas modalidades de línguas, já que é uma representação visual da ortografia da língua oral, além de estar integrada de variadas formas nas LS.

${ }^{5}$ SignWriting (SW) "é um sistema de escrita visual direta de sinais que é capaz de transcrever as propriedades sublexicais das línguas de sinais do mesmo modo como o Alfabeto Fonético Internacional”; é um tipo de alfabeto não arbitrário, ou seja, em que as formas das letras não são arbitrárias (CAPOVILLA; RAPHAEL; MAURICIO, 2012, p.169).

${ }^{6}$ Grosjean (2008) cita alguns exemplos: "'manually coded systems' (e. g. Seeing Essential English in the USA, Sign Supported English in the UK) as well as pidgin sign language (PSE), the sort of language used by hearing people who have not fully mastered the true sign language of the Deaf' (p. 223)
} 
podendo garantir a muitos surdos uma interação satisfatória. No que tange à língua utilizada para a escrita, assistimos a algumas mudanças nos últimos anos. Como relata Botelho (2002), há alguns anos, surdos com melhores condições financeiras tinham aparelhos de fax e usavam-nos para transmitir mensagens em português escrito em algumas situações. De alguma forma, a Libras era usada nas interações face a face, e o português era a língua da escrita. Porém, com as novas tecnologias, abrem-se outras possibilidades de uso da Libras e ampliam-se os usos do português escrito. Soma-se a isso o desenvolvimento, nos últimos anos, de formas de registro escrito das LS. Dito de outro modo, ao mesmo tempo em que a escrita do português ganha novo significado no uso dessas tecnologias que, inclusive, podem aproximar a escrita da interação face a face; a Libras também ganhou a possibilidade de ser utilizada "a distância" pelo compartilhamento de vídeos e também a possibilidade de ser escrita pelos surdos. Destaca-se aqui o uso contínuo de vídeos em Libras veiculados pela internet. Constatando a intensa produção desses vídeos, Marques e Oliveira (2012) propõem que essa forma de registro da Libras seja considerada uma forma de escrita, com uma ampliação do conceito de escrita e considerando vários benefícios do uso de vídeos em Libras na educação de pessoas surdas.

\section{Metodologia}

No Brasil, ainda temos poucos estudos que descrevem os usos da Libras e do português por surdos adultos em diferentes domínios do cotidiano. Assim, optamos pelo desenvolvimento de um estudo exploratório qualitativo, a fim de descrever aspectos relacionados à história linguística desses bilíngues, bem como identificar os domínios de uso da Libras e do português conforme proposta do Princípio da Complementaridade. Considerando então os objetivos da pesquisa, optamos pela condução de uma entrevista semiestruturada como procedimento de coleta de dados. Na entrevista semi-estruturada (ou focalizada), o entrevistador faz perguntas específicas, mas deixa que o participante responda em seus próprios termos (ALVES-MAZZOTTI; GEWANDSZNAJDER, 1999), além de poder introduzir determinados itens não previamente previstos conforme a especificidade do entrevistado. Considerando então que as experiências linguísticas são amplas e envolvem várias dimensões, buscamos, nas pesquisas mais amplas sobre bilinguismo e sobre o bilinguismo dos surdos, indicações sobre elementos essenciais na definição de perfis de bilíngues, chegando à definição de 3 grandes módulos que guiariam a geração de itens para a entrevista: (i) história de vida, (ii) comunicação face a face em diferentes domínios; (iii) 
comunicação a distância em diferentes domínios e usos da leitura e da escrita. Ao final da entrevista, perguntamos aos surdos também sobre alguns dados pessoais e sobre a surdez. As perguntas foram geradas em português e, posteriormente, foram traduzidas para a Libras, sendo registradas em glosas para servir de referência no momento das entrevistas, que foram conduzidas pela autora deste trabalho. Conforme o andamento das entrevistas, algumas perguntas precisaram ser adaptadas ou reformuladas para garantir a compreensão dos participantes. Abaixo apresentamos em português o roteiro da entrevista semi-estruturada.

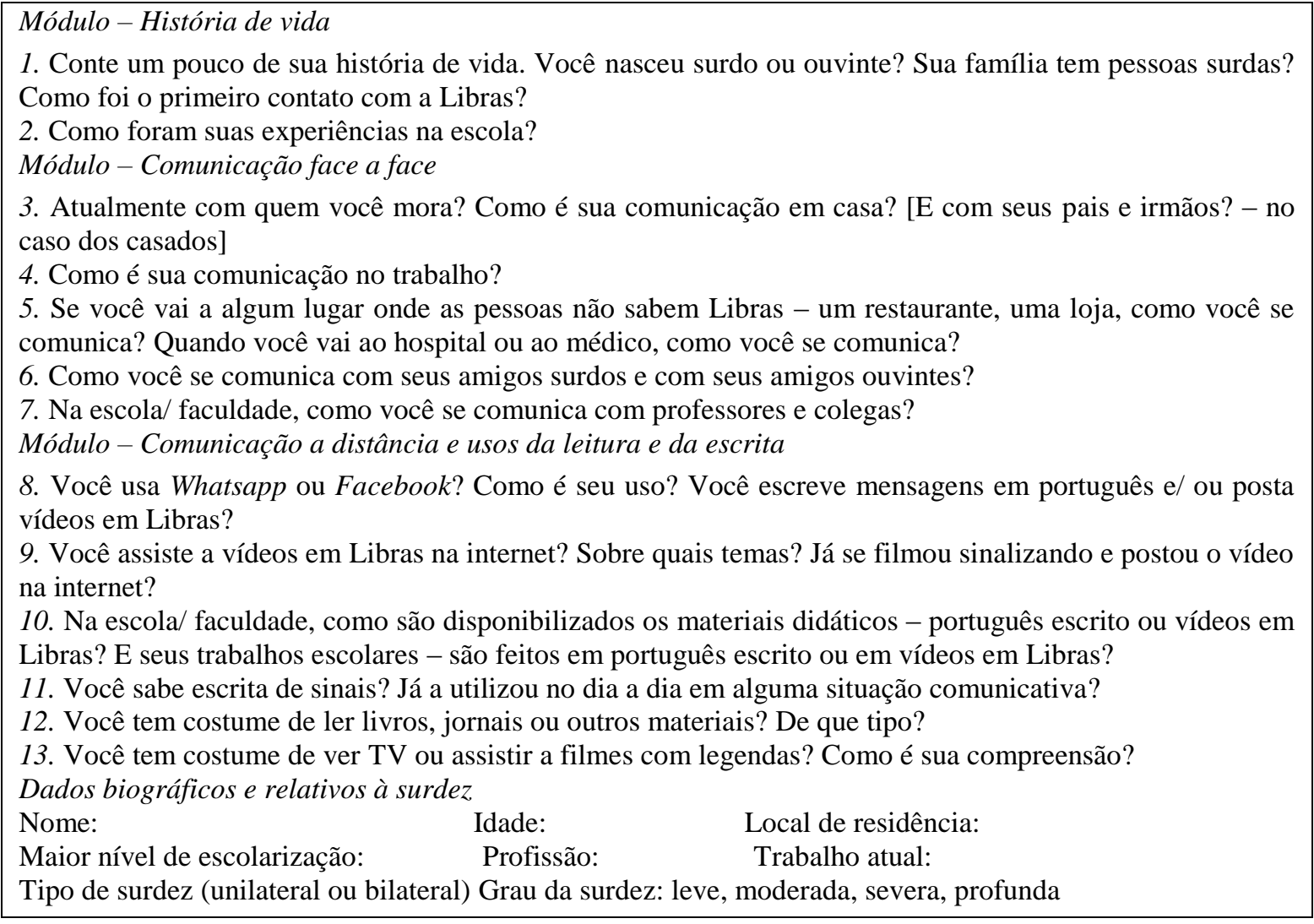
FIGURA 1: Roteiro da Entrevista Semi-Estruturada

Os participantes desta pesquisa foram 14 pessoas surdas, usuárias da Libras, com idades entre 18 e 70 anos, sendo 7 do sexo masculino e 7 do sexo feminino. Dos 14 participantes, 9 residem em Belo Horizonte (MG), 1 em Uberlândia (MG), 1 em Juiz de Fora (MG), 2 em Florianópolis (SC) e 1 em Belém do Pará (PA). O acesso aos participantes foi obtido por meio da rede de contatos da autora deste trabalho. Os únicos critérios utilizados para a seleção dos participantes foram: (i) ser usuário da Libras; e (ii) ter escolaridade mínima de Ensino Fundamental, para se garantirem certos usos da leitura e da escrita do português.

Todas as entrevistas foram conduzidas em Libras durante o período de abril de 2016 a agosto de 2016 pela autora deste trabalho, que tem fluência em Libras. As entrevistas foram 
conduzidas presencialmente ou a distância, por meio de software de interação por vídeo (Skype, por exemplo). No caso das entrevistas presenciais, essas foram realizadas em diferentes locais, dependendo da escolha e da disponibilidade dos participantes (residência ou local de trabalho dos participantes ou a Faculdade de Letras da UFMG). Antes do início das entrevistas, os participantes assistiram a um vídeo com a tradução para a Libras do termo de consentimento livre e esclarecido e, em seguida, leram o documento original em português e, no caso de dúvidas, essas foram sanadas pela pesquisadora em Libras. As entrevistas foram gravadas em vídeo e posteriormente analisadas, sendo que, alguns trechos foram traduzidos para viabilizar a busca rápida de informações específicas em documentos do Microsof Word e a posterior divulgação dos dados em publicações.

\section{Análise dos dados}

Na figura 2, apresentamos algumas características dos participantes no tocante à surdez, condição auditiva dos pais, contato com a Libras, escolaridade e profissão. Todos os participantes desta pesquisa são filhos de pais ouvintes, o que representa a realidade vivida pela maioria das pessoas $\operatorname{surdas}^{7}$. Com exceção da participante 8 , a maioria dos participantes ficou surda no período pré-lingual, o que indica, juntamente com o tipo de surdez relatada, que eles certamente não adquiriram o português como L1 no seio da família. Os participantes desta pesquisa apresentam idades de início de aquisição da Libras bastante diversas, indo de 3 a 23 anos de idade. Boudreault e Mayberry (2006) classificaram seus participantes de pesquisa em 3 grupos, a saber: (i) aprendizes nativos - adquiriram a LS desde o nascimento; (ii) aprendizes precoces de L1 - adquiriram a LS quando matriculados numa escola para surdos entre as idades de 5 a 7 anos; e aprendizes tardios de L1 - adquiriram a LS entre os 8 e 13 anos (idade-limite dos aprendizes da pesquisa). Considerando esse agrupamento, não temos falantes nativos em nossa pesquisa; 6 são aprendizes precoces, com idades de início de aquisição da LS variando de 5 a 7 anos; 8 são aprendizes tardios, com idades variando de 9 a 23 anos. Realmente, no que tange à idade de início da aquisição, a diversidade dos surdos é bem grande, e os contextos de aquisição são bastante complexos, sendo que o perfil dos surdos entrevistados evidencia a dificuldade de encontrar sujeitos nativos ou com perfis

\footnotetext{
${ }^{7}$ Nos Estados Unidos, estima-se que mais de 90\% dos surdos sejam filhos de pessoas ouvintes (SCHIEN; DELK, 1974 apud MAYBERRY, 2007). Porém, apesar de tal estimativa ser feita no contexto americano, é comum que pesquisadores de outros países a tomem como referência. No entanto, Costello, Fernández e Landa (2006) afirmam que o uso de tal estimativa para outras populações surdas precisa ser questionado, devido a vários fatores, afirmando que há situações em que a população surda filha de ouvintes é ainda maior.
} 
próximos ao de nativos (COSTELLO; FERNÁNDEZ; LANDA, 2006). Para a maioria dos participantes, a aquisição da LS não pôde ocorrer desde a primeira infância, no interior da família, mas ocorreu com a entrada na escola, o que confirma a importância da escola para o desenvolvimento linguístico da maioria dos surdos (PLAZA-PUST, 2012). 


\begin{tabular}{|c|c|c|c|c|c|c|}
\hline $\begin{array}{l}\text { Partici- } \\
\text { pante/ } \\
\text { sexo* }\end{array}$ & $\begin{array}{c}\text { Período de } \\
\text { ocorrência da } \\
\text { surdez }\end{array}$ & Tipo de surdez relatada & $\begin{array}{c}\text { Condição } \\
\text { auditiva dos } \\
\text { pais }\end{array}$ & $\begin{array}{c}\text { Início de aquisição da Libras - } \\
\text { idade e local }\end{array}$ & Escolaridade & Profissão atual \\
\hline 1f & 2 meses & Bilateral profunda & Ouvintes & 9 anos - escola especial para surdos & Ensino Superior & Auxiliar administrativo \\
\hline $2 \mathrm{~m}$ & 2 anos & Não informou & Ouvintes & 9 anos - escola especial para surdos & Ensino Superior & $\begin{array}{l}\text { Professor e servidor } \\
\text { público na área judiciária }\end{array}$ \\
\hline $3 m$ & Nasceu surdo & Bilateral profunda & Ouvintes & 11 anos - escola especial para surdos & $\begin{array}{l}\text { Ensino Superior } \\
\text { em andamento }\end{array}$ & $\begin{array}{l}\text { Agente educacional e } \\
\text { cartunista }\end{array}$ \\
\hline $4 m$ & Nasceu surdo & Bilateral profunda & Ouvintes & 6 anos - escola especial & $\begin{array}{l}\text { Ensino Superior } \\
\text { em andamento }\end{array}$ & $\begin{array}{l}\text { Tradutor e guia-intérprete/ } \\
\text { estudante }\end{array}$ \\
\hline $5 \mathrm{~m}$ & Nasceu surdo & $\begin{array}{l}\text { Bilateral/ não soube } \\
\text { especificar o grau }\end{array}$ & Ouvintes & 5 anos - escola especial & $\begin{array}{l}\text { Ensino Médio em } \\
\text { andamento }\end{array}$ & Estudante \\
\hline $6 f$ & Nasceu surda & Bilateral profunda & Ouvintes & $\begin{array}{l}\text { Tratamento fonoaudiológico (?) e } \\
\text { escola comum. }\end{array}$ & $\begin{array}{l}\text { Ensino Superior } \\
\text { em andamento }\end{array}$ & $\begin{array}{l}\text { Tradutora e guia- } \\
\text { intérprete/ estudante }\end{array}$ \\
\hline $7 f$ & 10 meses & $\begin{array}{l}\text { Bilateral/ não soube } \\
\text { especificar o grau }\end{array}$ & Ouvintes & 5 anos - escola especial para surdos & Ensino Médio & Desempregada \\
\hline $8 f$ & 11 anos & $\begin{array}{l}\text { Bilateral, de severa a } \\
\text { profunda }\end{array}$ & Ouvintes & 23 anos - entidade de surdos & $\begin{array}{l}\text { Ensino Superior/ } \\
\text { Mestrado }\end{array}$ & Professora de Libras \\
\hline $9 m$ & Nasceu surdo & Bilateral profunda & Ouvintes & $\begin{array}{l}19 \text { anos - faculdade, curso de Libras } \\
\text { e contato com surdos }\end{array}$ & Ensino Superior & Professor de Libras \\
\hline $10 \mathrm{~m}$ & 2 anos & $\begin{array}{l}\text { Bilateral profunda num } \\
\text { ouvido/ não soube } \\
\text { especificar o grau do outro }\end{array}$ & Ouvintes & $\begin{array}{l}5 \text { anos - escola especial/ } 17 \text { anos - } \\
\text { escola comum }\end{array}$ & Ensino Superior & Professor de Libras \\
\hline 11f & Nasceu surda & Bilateral severa & Ouvintes & $\begin{array}{l}15 \text { anos - escola comum onde havia } \\
\text { turmas somente de alunos surdos }\end{array}$ & Ensino Superior & $\begin{array}{l}\text { Assistente de } \\
\text { Departamento Pessoal/ } \\
\text { instrutora de Libras }\end{array}$ \\
\hline $12 \mathrm{~m}$ & 3 anos & $\begin{array}{l}\text { Bilateral/ não soube } \\
\text { especificar o grau }\end{array}$ & Ouvintes & 6 anos - escola especial para surdos & Ensino Médio & $\begin{array}{l}\text { Funcionário terceirizado } \\
\text { da Justiça Federal }\end{array}$ \\
\hline $13 \mathrm{f}$ & Nasceu surda & $\begin{array}{l}\text { Bilateral/ não soube } \\
\text { especificar o grau }\end{array}$ & Ouvintes & 3 anos - escola especial para surdos & Ensino Superior & Desempregada \\
\hline $14 \mathrm{f}$ & 8 meses & Bilateral profunda & Ouvintes & $\begin{array}{l}\text { Primeira infância - contato com } \\
\text { primos surdos/ } 6 \text { anos - escola } \\
\text { especial }\end{array}$ & Ensino Superior & $\begin{array}{l}\text { Professora de Libras/ } \\
\text { aposentada }\end{array}$ \\
\hline
\end{tabular}

FIGURA 2: Dados dos participantes da pesquisa

$* \mathrm{~F}$ - feminino $\mathrm{M}$ - masculino 
Além da idade de contato com o português, as oportunidades de aprendizagem do português oral são importantes para compreendermos o perfil desses bilíngues. Muitos surdos tiveram dificuldade de relatar detalhes ou precisar a duração do tratamento fonoaudiológico, com exceção dos participantes 6 e 9, que frequentaram o tratamento desde crianças, por mais de 10 anos. Alguns surdos frequentaram o tratamento por cerca de 3 anos ou menos (participantes 2, 3, 4, 10, 11). De modo geral, poucos surdos se mostraram seguros ao falar de suas habilidades de uso da fala, com exceção dos participantes 2, 8 e 9: o participante 2, disse que sente que sua fala é compreensível e apenas não se sente confortável pelo fato de não controlar bem o volume de sua voz; já os participantes 8 e 9 aprenderam Libras na idade adulta, tendo se comunicado ao longo de muitos anos predominantemente pelo português.

No que tange à escolaridade, dos 14 participantes, 11 estão cursando ou já concluíram o Ensino Superior, 2 já concluíram o Ensino Médio, e 1 ainda está cursando o Ensino Médio. Esse perfil de participantes acabou se delineando devido à forma de contato com os participantes, que se deu pela rede de contatos da autora do trabalho. Ainda que tenhamos consciência de que a comunidade surda enfrenta dificuldades de acesso ao ensino superior, o perfil de surdos com mais alto nível de escolaridade não compromete este estudo exploratório, pois permite visualizar variadas práticas de uso das línguas, especialmente no que tange à leitura e à escrita do português.

\section{Uso das línguas na comunicação face a face}

$\mathrm{Na}$ entrevista, foram abordadas as formas de comunicação face a face em diferentes domínios cotidianos, como família, trabalho, amigos, comércio. Neste trabalho, vamos restringir a análise à comunicação na família e no trabalho, como sintetizado na figura 3 , em que aparecem as línguas utilizadas conforme a preferência dos entrevistados. Para analisar a questão da comunicação em família, consideramos, no caso dos surdos já casados, a comunicação em sua família de origem, com pais e irmãos, bem como em sua família imediata, formada por ele, cônjuge/ companheiro e filhos. Dos 14 surdos entrevistados, 8 relataram usar o português oral como a primeira opção de comunicação com a família, sendo que, se houver algum problema de comunicação, então eles recorrem a outras formas de comunicação como o uso do português escrito, de gestos, de alguns sinais da Libras mais básicos e do alfabeto manual. Além desses 8 participantes que usam predominantemente o português oral, a participante 1 relatou que usa o português escrito, pois a família tem dificuldades de compreender suas vocalizações. Dos outros 5 participantes, 3 relataram o uso 
da Libras e do português; 1 participante relatou que usa Libras e português oral simultaneamente; e 1 relatou usar a Libras para se comunicar com sua mãe, que faz a mediação de suas interações com outros membros da família.

O português aparece então como a língua dominante na comunicação com a família de origem para 9 dos 14 participantes. Porém, o uso da modalidade oral do português precisa ser problematizado, já que uma das diferenças dos bilíngues surdos para outros bilíngues é o fato de que certas habilidades na língua majoritária podem nunca ser completamente desenvolvidas, como é o caso da fala (GROSJEAN, 2008). Assim, apesar de o português ser a língua dominante no cotidiano das famílias, há problemas de comunicação e, com exceção de uma surda que aprendeu Libras tardiamente, todos os participantes que usam o português oral afirmaram que usam outras estratégias de comunicação além da oralidade, tais como português escrito, gestos, sinais e alfabeto manual. Isso evidencia a complexidade das situações comunicativas em que se envolvem esses indivíduos, considerando a diversidade de seus níveis de proficiência em LS e na língua majoritária oral e/ ou escrita, assim como os baixos níveis de proficiência em LS de seus interlocutores. Soma-se a isso outra característica já apontada por Grosjean (2008, p.226) sobre o bilinguismo dos surdos - a complexidade dos padrões de uso das línguas e de formas mescladas. Em algumas entrevistas, os participantes relatavam situações em que ocorria a comunicação simultânea com familiares (fala e sinais).

\begin{tabular}{|c|c|c|c|}
\hline & Família de origem & Família imediata & Trabalho \\
\hline 1 & $\begin{array}{l}\text { (1) português escrito } \\
\text { (2) português oral }\end{array}$ & (1) Libras & (1) Português oral (2) português escrito \\
\hline 2 & (1) Português oral & (1) Libras & (1) Português oral (2) Português escrito \\
\hline 3 & (1) Português oral & Não se aplica & (1) Libras \\
\hline 4 & $\begin{array}{l}\text { (1) Português oral } \\
\text { (2) Português escrito }\end{array}$ & $* * *$ & (1) Libras \\
\hline 5 & (1) Português oral & & Estudante \\
\hline 6 & $\begin{array}{l}\text { (1) Libras e português } \\
\text { oral }\end{array}$ & $* * *$ & (1) Libras \\
\hline 7 & (1) Português oral & $* * *$ & Está desempregada. \\
\hline 8 & (1) Português oral & (1) Libras e português oral & (1) Libras e português (oral ou escrito) \\
\hline 9 & (1) Português oral & $* * *$ & (1) Libras e português (oral ou escrito) \\
\hline 10 & (1) Português oral & $* * *$ & (1) Libras e português oral \\
\hline 11 & (1) Libras e português & (1) Libras & (1) Libras e português \\
\hline 12 & $\begin{array}{l}\text { (1) Libras/ mediação da } \\
\text { mãe }\end{array}$ & $* * *$ & (1) Libras, português oral e escrito. \\
\hline 13 & $\begin{array}{l}\text { (1) Libras e comunicação } \\
\text { simultânea }\end{array}$ & $* * *$ & Está desempregada. \\
\hline 14 & $\begin{array}{l}\text { (1) Português oral } \\
\text { (2) Libras }\end{array}$ & $\begin{array}{l}\text { (1) Libras, português oral e } \\
\text { comunicação simultânea }\end{array}$ & Está aposentada. \\
\hline
\end{tabular}


No que tange à língua utilizada na "família imediata", consideramos o caso dos 5 participantes já casados: 4 deles tinham cônjuges também surdos e 1 surda morava com sua filha ouvinte, que é fluente em Libras. 4 participantes relataram usar a Libras como a primeira opção de comunicação em casa. Uma participante, que adquiriu Libras já na idade adulta, relatou que seu marido é um surdo oralizado, que usa geralmente o português com ele e com seu filho ouvinte, apesar de ultimamente ela relatar se sentir mais segura quando utiliza a Libras.

Em relação ao uso das línguas no trabalho, consideramos os dados dos 10 participantes que estavam trabalhando no momento das entrevistas. Desses 10 surdos, 6 atuam na área de Libras e educação, convivendo bastante com usuários da Libras: 2 são tradutores de Librasportuguês e guias-intérprete (participantes 4 e 6) afirmaram que, no trabalho, a comunicação face a face é toda realizada em Libras; 3 eram professores de Libras (participantes 8, 9 e 10) e relataram outros detalhes, indicando, além do uso da Libras, o uso de português oral com alunos, ou de português oral e/ ou escrito para resolver questões administrativas no trabalho, já o agente educacional (participante 3) afirmou usar a Libras na entidade de surdos onde trabalha. Nos casos dos outros 4 participantes que não atuam na área de Libras, 2 afirmaram que o português é a principal língua utilizada no trabalho. Já os outros 2 participantes relataram haver pessoas que sabem Libras no ambiente de trabalho. Pelos casos relatados, observa-se que a língua dominante nas interações face a face no trabalho vai depender da área de atuação do surdo. Se for algum profissional envolvido na área da surdez, a LS tende a ser a língua mais utilizada no trabalho, ainda que o português oral seja também utilizado. Já os surdos que não trabalham na área da surdez tendem a utilizar mais o português oral e/ ou escrito, seja com os colegas ouvintes ou mesmo com o público que precisa atender, ou usam a Libras para uma comunicação mais básica e/ ou vão depender da mediação de intérpretes, além de usar outras formas de apoio à interação.

\section{Uso das línguas na comunicação a distância}

O terceiro bloco de perguntas na entrevista visava identificar práticas mais amplas de leitura e escrita da Libras e do português, além de práticas de uso de vídeos em Libras. Dos 14 surdos entrevistados, 4 já haviam frequentado disciplinas ou cursos de SignWritting. Ao serem questionados sobre o uso social da escrita de sinais, os 4 surdos afirmaram que não o utilizaram fora do ambiente universitário ou do curso, exceto um surdo que relatou que o 
único uso social que fez foi o registro de um sinal novo que ensinava a um amigo. Ao contrário do que afirmam Capovilla, Raphael e Mauricio (2012, p.170), apesar de já ser mais conhecida na comunidade surda, especialmente entre os surdos mais escolarizados, parece, pelo menos no caso dos participantes deste trabalho, que a escrita de sinais ainda não tem sido utilizada socialmente.

Essa situação é particularmente interessante para se refletir sobre como as línguas se distribuem nos diferentes domínios de uso e como as modalidades sinalizada, oral e escrita são usadas nesses domínios. O português acaba sendo a língua da escrita, devido à falta de um sistema de escrita de sinais suficientemente difundido. Porém, atualmente, com os vários recursos tecnológicos, a Libras também passa a ser utilizada por meio do registro em vídeos veiculados principalmente por meio da internet, o que tem propiciado o desenvolvimento de diferentes gêneros textuais em Libras. A esse respeito, todos os participantes relataram assistir a vídeos em Libras na internet. Em relação a postar vídeos, essa é uma prática menos comum, relatada por 6 participantes; os outros participantes disseram que não se sentem confortáveis em postar vídeos devido à exposição da imagem. Os temas e/ ou os gêneros textuais dos vídeos em Libras são variados, indo de convites de festas ou eventos, divulgação de palestras, a mensagens e depoimentos religiosos, etc.

Interessante observar que, em alguns domínios, o uso de vídeos em Libras aparece como uma contraparte para textos escritos em português. Em relação ao uso do aplicativo Whatsapp, a maioria dos surdos afirmou que prefere usar o português escrito para interagir, por considerar mais prático e rápido. Porém, 7 surdos (participantes 2, 3, 5, 6, 9, 12, 13) também relataram que se filmam e postam vídeos em Libras direcionados a outros surdos, com o objetivo de esclarecer alguma situação de incompreensão vivenciada com o uso do português escrito. No caso dos estudantes de Letras-Libras, a Libras aparece também como a língua dos trabalhos acadêmicos. Os participantes 4, 6 e 8 relataram que produziram trabalhos acadêmicos em Libras por meio de vídeos e também assistiram a vídeos com textos didáticos em Libras disponibilizados pelos professores. A participante 8 relatou que gosta de usar os dois recursos - textos escritos em português e textos gravados em Libras, já os participantes 6 e 8 relataram preferir ler os textos em português, por acharem-nos mais completos e claros quanto aos conceitos científicos. Interessante observar que, em alguns casos, a escolha do português escrito passava pela praticidade de uso dessa língua em determinados meios de comunicação. Vários surdos disseram que é muito mais prático ler e escrever mensagens de Whatsapp em português do que filmar e assistir aos vídeos em Libras. Outros participantes destacaram a importância de os vídeos em Libras serem curtos, pois, ao contrário, seria muito 
mais cansativo assistir aos vídeos do que ler mensagens em português.

Identificamos também, ao longo das entrevistas, várias práticas de leitura e escrita do português que perpassam vários domínios da vida desses bilíngues, como o trabalho, a escola/ faculdade, entre outros. Algumas práticas são bastante comuns entre eles - por exemplo, ler e escrever mensagens de Whatsapp ou ler e escrever textos e mensagens no Facebook, sendo relatadas por praticamente todos os surdos, não se diferenciando entre surdos com mais ou menos escolaridade. Além disso, muitos surdos relataram práticas de leitura e escrita escolares - ler textos didáticos e/ ou artigos científicos; escrever trabalhos escolares; além de práticas específicas do ambiente de trabalho, como lidar com programas, escrever e-mails mais formais; etc. Alguns surdos relataram o uso do português para o lazer: ler livros literários (principalmente de histórias reais), ler histórias em quadrinhos, ler clássicos da literatura adaptados para quadrinhos, entre outros. Tais práticas parecem ser mais indicativas de níveis mais altos de proficiência na leitura em português.

\section{Considerações finais}

Este estudo pretendeu descrever, de forma exploratória, aspectos ligados à história linguística dos participantes e os domínios de uso da Libras e do português no cotidiano. A análise das entrevistas aponta para alguns importantes fatores que marcam a experiência surda no uso das línguas e precisam ser considerados em pesquisas sobre o bilinguismo dos surdos, inclusive alguns já indicados em outras pesquisas (GROSJEAN, 1992, 2008; MAYBERRY, 2007, entre outros), a saber: (i) o período de ocorrência da surdez; (ii) a idade de aquisição da LS e a forma de contato, o que aponta para a diversidade de bilíngues surdos nesse aspecto e a dificuldade de encontrar surdos nativos de LS, além da importância da escola como local de contato com a LS; (iii) e a questão do tratamento fonoaudiológico e das possibilidades de desenvolvimento da oralidade para a comunicação. Pela análise dos relatos sobre o uso da Libras e do português, pode-se dizer que essas duas línguas assumem diferentes funções para os surdos bilíngues, sendo utilizadas conforme diferentes objetivos, domínios e pessoas, como propõe o Princípio da Complementaridade. Por exemplo: o português acaba sendo a principal língua das interações na família de origem para muitos dos surdos entrevistados; já na família formada pelos surdos, sendo os cônjuges também surdos, a Libras é a língua mais usada em casa. Nos casos de surdos que não atuam na área da surdez, o português tende a ser a língua do trabalho; enquanto que, para os surdos que atuam na área da educação de surdos, a Libras tende a ser a língua mais utilizada nesse domínio. 
Com a análise dos dados, pode-se dizer que vários fatores interferem na escolha de uma língua pelos participantes, além de questões relativas aos objetivos, domínios e pessoas, como propõe o Princípio da Complementaridade, mas também a possibilidade de uso mais satisfatório da língua oral, a disponibilidade e as funcionalidades de meios de comunicação, entre outros. Como já apontado por Grosjean (2008), certas habilidades na língua oral podem nunca ser completamente desenvolvidas no caso de bilíngues surdos, como é a produção oral e a compreensão. Essa diferença dos surdos tem implicações nos "modos interativos" escolhidos por eles em interações face a face como, por exemplo, o uso de vários elementos de apoio na comunicação oral (gestos e fala, sinais e fala, fala e escrita, etc.), como ocorre em algumas famílias. No que tange às possibilidades trazidas pelas novas tecnologias para o uso do português escrito e da LS não presencial, a utilização de vídeos em Libras em situações diversas que oferecem aos surdos a possibilidade de registro dessa língua, configurando, ainda que com ressalvas, uma espécie de contrapartida à escrita do português. Não havendo um uso social expressivo da escrita de sinais entre os entrevistados, os vídeos em Libras são utilizados como forma alternativa de registro como é o caso de artigos científicos, textos didáticos, convites, entre outros.

Finalmente, destaca-se que esta pesquisa traz implicações para as políticas linguísticas voltadas para as pessoas surdas, ao destacar o papel da escola como espaço privilegiado de contato dos surdos com a Libras e o português escrito. Nesse sentido, confirma-se o que já foi apontado também por outras pesquisas em relação ao papel proeminente da educação no bilinguismo dos surdos, sendo que a forma como a educação responde às necessidades linguísticas dos surdos tem sido um tema recorrente nas pesquisas sobre bilinguismo intermodal (PLAZA-PUST, 2012).

\section{REFERÊNCIAS}

ALVES-MAZZOTTI, A. J.; GEWANDSZNAJDER, F. O método nas ciências naturais e sociais: pesquisa quantitativa e qualitativa. 2. Ed. São Paulo: Pioneira, 1999.

ANN, J. 2001. Bilingualism and Language Contact. In: LUCAS, C. (Ed.) The Sociolinguistics of Deaf Communities. New York: Cambridge University Press, 2001. p.3360 .

BOTELHO, P. Educação Inclusiva para Surdos: Desmistificando pressupostos. In: I SEMINÁRIO INTERNACIONAL SOCIEDADE INCLUSIVA, 1999, Belo Horizonte. Anais do I Seminário Internacional Sociedade Inclusiva. Belo Horizonte: PUC Minas Gerais, 1999. p. $1-5$.

BOTELHO, P. Linguagem e Letramento na Educação de Surdos: ideologias e práticas 
pedagógicas. Belo Horizonte: Autêntica, 2002.

BOUDREAULT, P.; MAYBERRY, R. I. Grammatical processing in American Sign Language: Age of first-language acquisition effects in relation to syntactic structure. Language and Cognitive Processes, v. 21, n. 5, p. 608-635, 2006.

CAPOVILlA, F. C.; RAPHAEL, W. D.; MAURICIO, A. C. Parte 1: SignWritting: como escrever a articulação visível dos sinais da Libras. In: CAPOVILLA, F. C.; RAPHAEL, W. D.; MAURICIO, A. C. Novo Deit-Libras: Dicionário Enciclopédico Ilustrado Trilíngue da Língua de Sinais Brasileira (Libras) baseado em Linguística e Neurociências Cognitivas. 2 Ed. rev. e ampl. São Paulo: Editora da Universidade de São Paulo: Inep: CNPq: Capes: Obeduc, 2012. Vol. 1., p. 168-171.

CARROLL, R.; LUNA, D. The other meaning of fluency: Content accessibility and language in advertising to bilinguals. Journal of Advertising, 40 (3), 73-84, 2011.

COSTELLO, B.; FERNÁNDEZ, J.; LANDA, A. O sinalizante nativo não-(existente): pesquisa em língua de sinais em uma pequena população surda. In: Questões Teóricas das Pesquisas em Línguas de Sinais - Coletânea de trabalhos apresentados em "9 Theoretical Issues In Sign Language Research Conference". Florianópolis (SC), Brasil, 2006. p. 351-366. CRUZ, C.; PIZZIO, A.; QUADROS, R. Avaliação da discriminação fonêmica do português brasileiro e da Língua de Sinais Brasileira em crianças ouvintes bilíngues bimodais e em crianças surdas usuárias de implante coclear. Revista da ABRALIN. v. 14, n.1, jan./jun., p. 337-360, 2015.

Disponível em:http://ojs.c3sl.ufpr.br/ojs/index.php/abralin/article/view/42824/25976. Acesso em: 02 jul. 2016.

GROSJEAN, F. The bilingual and the bicultural person in the hearing and in the deaf world. Sign Language Studies, vol. 77, p. 307-320, 1992.

GROSJEAN, F. Studying Bilinguals. New York: Oxford University Press, 2008.

GROSJEAN, F. Bilingualism: A Short Introduction. In: GROSJEAN, F.; LI, P. (Eds). The

Psycholinguistics of Bilingualism. Malden, MA: Willey-Blackwell, Inc., 2013. p. 5-25.

GROSJEAN, F. The Complementarity Principle and its impact on processing, acquisition, and dominance. In: TREFFERS-DALLER, J.; SILVA CORVALAN, C. (Eds.). Language dominance in bilinguals: Issues of measurement and operationalization. Cambridge: Cambridge University Press, 2016. p.66-84.

MAYBERRY, R. I. When timing is everything: Age of first-language acquisition effects on second-language learning. Applied Psycholinguistics, v. 28, p. 537-549, 2007.

MARQUES, R. R. ; OLIVEIRA, J. S.A Normatização de artigos acadêmicos em Libras e sua relevância como instrumento de constituição de corpus de referência para tradutores. In: III Congresso Nacional de Pesquisas em Tradução \& Interpretação de Libras e Língua Portuguesa, 2012, Florianópolis. Anais do III Congresso Nacional de Pesquisas em Tradução \& Interpretação de Libras, 2012. Disponível em: http://www.congressotils.com.br/anais/anais/tils2012_metodologias_traducao_marquesoliveir a.pdf. Acesso em: 12 de setembro de 2016.

MORALES-LÓPEZ, E.; ALIAGA-EMETRIO, D.; ALONSO-RODRÍGUEZ, J. A.; BOLDÚMENASANCH, R. M.; GARRUSTA-RIBES, J.; GRASS-FERRER, V. Deaf People in Bilingual Speaking Communities: The Case of Deaf People in Barcelona. In: LUCAS, C. (Ed.) Turn-Taking, Fingerspelling, and Contact in Signed Languages. Washington, D.C.: Gallaudet University Press, 2002. p. 107-155.

PLAZA-PUST, C. Deaf education and bilingualism. In: PFAU, R.; STEINBACH, M.; WOLL, B. (Eds.). Sign Language: An International Handbook. Berlin, Germany: De Gruyter Mouton, 2012. p. 949-979.

QUADROS, R. M. Contextualização dos estudos linguísticos sobre a Libras no Brasil. In: QUADROS, R. M.; STUMPF, M. R.; LEITE, T. A. (org.). Estudos da língua brasileira de 
sinais. Série Estudos da Língua de Sinais. V. I. Florianópolis: Insular, 2013. p.15-36 QUADROS, R. M.; CRUZ, C. R. Língua de Sinais: Instrumentos de Avaliação. Porto Alegre: Artmed, 2011.

QUADROS, R. M. de; PIZZIO, A. L.; CRUZ, C. R.; SOUSA, A. N. de. Mosaico da Linguagem das crianças bilíngues bimodais: estudos experimentais. Rev. bras. linguist. apl. [online]. Vol.16, n.1, p.1-24, 2016.

SOUSA, A. N.; QUADROS, R. M. de. Uma análise do fenômeno "alternância de línguas" na fala de bilíngues intermodais (Libras e Português). ReVEL, v. 10, n. 19, p. 327-346, 2012.

STOKOE, W. C. (1960) Sign Language Structure: An Outline of the Visual Communication Systems of the American Deaf. Journal of Deaf Studies and Deaf Education, v. 10, n.1, p. 337, 2005.

Recebido em: 31/03/2017. Aceito em: 04/06/2017. 